\title{
A STUDY OF ELDERLY UNNATURAL DEATHS IN MEDICOLEGAL AUTOPSIES AT DAKAHLIA LOCALITY
}

\author{
$\mathcal{B Y}$ \\ Essam M. Ali; Amal A. Elbakry \& Mahmoud A. Ali * \\ Departments of Forensic Medicine and Clinical Toxicology Faculty of Medicine, Mansoura University \\ ; Mansoura Medicolegal Institute, Ministry of Justice *, Egypt
}

\begin{abstract}
The main aim of this study was to determine the causes and epidemiological aspects of unnatural deaths in elderly. Data were collected on 681 males and female victims of unnatural deaths aged 50 years or more from the total number of 2967 autopsies performed in Mansoura Medicolegal Centre (Ministry of Justice) over a ten-year period, from year 1996 to 2005. There were 516 male victims and 165 female victims. Unnatural deaths were higher in rural (83.55\%) than in urban (16.45\%) areas. Homicidal deaths were the most common manner of unnatural deaths (83.85\%), followed by accidental deaths (14.98\%) then suicidal deaths (1.17\%). Traumas were the most common cause of unnatural death (78.71\%), followed by undetermined causes (13.36\%) and toxicological causes (7.93\%). The most common causes of traumatic deaths were blunt head injuries (35.83\%) followed by stab in the chest (16.04\%), burn (12.31\%), blunt injuries in abdomen and chest (10.07\%), firearm injuries in the head and trunk (8.02\%), strangulation (7.28\%), stab in the abdomen (3.36\%), smothering (3.17\%), cut throat (1.68\%), throttling $(1.49 \%)$ then hanging $(0.75 \%)$. Carbamate poisoning was the most common cause of toxicological deaths (48.15\%) followed by organophosphorus poisoning (27.77\%), ethyl alcohol poisoning (11.11\%), barbiturate poisoning $(7.41 \%)$ then zinc phosphide poisoning $(5.56 \%)$.
\end{abstract}

\section{INTRODUCTION}

Unnatural deaths are deaths which are not solely or totally due to disease and or aging process. These deaths may be accidental, suicidal, homicidal or undetermined. Accident applies when an injury or poisoning causes death and there is little or no evidence that the injury or poisoning occurred with intent to harm or cause death. Suicide results from an injury or poisoning as a result of an intentional, self-inflicted act committed to do self harm or cause death of one's self. Homicide means taking of the life of one person by another by any mean. Undetermined deaths is a term used when information pointing to one manner of death is no more compelling than one or more other competing manners of death (Davis, 1997). 
Several factors such as age, sex, religion, ethnicity, socioeconomic status, literacy, weapon and others influence the act of homicide (Kumar et al., 2005).

Medicolegal autopsies not only give the cause, origin, and manner of death but also make available important statistical data related to legal incidents in the area where the autopsies were conducted (Vougiouklakis and Tsiligianni, 2006).

One million people die annually worldwide due to suicides and homicides alone. Another 2.5 million people die each year because of accidents, burns, drowning, poisoning and falling from heights and from disaster. With growth in the population, day to day frustration, stressful life, competition, and modern needs, the incidence of suicide as well as homicide is on the increase worldwide (Ambade et al., 2007).

The main objective of this present study was to determine the different epidemiological aspects of unnatural deaths in males and female persons aged 50 years or more in Dakahlia locality over a period of 10 years extending from January 1996 to December 2005.

\section{MATERIAL AND METHODS}

A retrospective research was conducted on the cases of unnatural deaths in Dakah- lia locality over a period of 10 years extending from January 1996 to December 2005. The material for the present study comprised 681 autopsied males and female victims aged 50 years or more out of 2967 performed autopsies during this year period.

For the present study all files in Mansoura Medicolegal Institute that mentioned accident, suicide, homicide as manner of death were reviewed. These files include completed autopsy reports, toxicological reports furnished by the Laboratory located in the Department and history files provided by the police. The examination of the data included the age, the gender and residency of the victims, manner of death and causes of death.

The data so procured was compiled and analyzed by the computer database SPSS (version 12.0).

\section{RESULTS}

The number of unnatural deaths in elderly persons aged 50 years or more allover the period of study was 681 (516 males and 165 females) which represent $22.95 \%$ of total unnatural deaths. $75.77 \%$ of unnatural deaths in elderly was males $(55.51 \%$ aged from 50 - 60 years and $20.26 \%$ aged above 60 years) whereas $24.23 \%$ were females (15.57\% aged from 50 - 60 years and $8.66 \%$ aged above 60 years) (Figure 1). The 
maximum number of cases occurred in 2005 (95 cases).

Unnatural deaths were higher in rural $(83.55 \%)$ than in urban $(16.45 \%)$ areas (Figure 2). Homicidal deaths were the most common manner of unnatural deaths $(83.85 \%)$, followed by accidental deaths $(14.98 \%)$ then suicidal deaths (1.17\%) (Figure 3). Traumas were the most common cause of death $(78.71 \%)$, followed by undetermined causes $(13.36 \%)$ and toxicological causes $(7.93 \%)$ (Figure 4 ).

The most common causes of traumatic deaths were blunt head injuries (35.83\%) followed by stab in the chest $(16.04 \%)$, burn $(12.31 \%)$, blunt injuries in abdomen and chest $(10.07 \%)$, firearm injuries in the head and trunk $(8.02 \%)$, strangulation $(7.28 \%)$, stab in the abdomen $(3.36 \%)$, smothering $(3.17 \%)$, cut throat $(1.68 \%)$, throttling $(1.49 \%)$ then hanging $(0.75 \%)$ (Figure 5).

Carbamate poisoning was the most common cause of toxicological deaths $(48.15 \%)$ followed by organophosphorus poisoning $(27.77 \%)$, ethyl alcohol poisoning $(11.11 \%)$, barbiturate poisoning $(7.41 \%)$ then zinc phosphide poisoning $(5.56 \%)$ (Figure 6).

\section{DISCUSSION}

Allover the period of this study the per- centage of unnatural deaths in elderly persons aged 50 years or more represented $22.95 \%$ of total unnatural deaths. Every year, throughout the ten-year study period, the number of unnatural deaths in elderly males was more than elderly females. These findings are in agreement with study of Mohanty et al. (2005) who observed that the numbers of males were more as compared to the female victims of homicidal deaths in the same age group. Milroy and Ranson (1997) also reported a similar finding in Victoria, Australia. Men are more commonly victims perhaps as they are generally working outdoors and are more exposed to stress, frustrations and violence. Nevertheless, women often become victims of domestic homicides due to physical disadvantage and incapability of resistance to violence (Kumar et al., 2005).

Unnatural deaths were found to be higher in rural than in urban areas in this study. This observation is in agree with the study of Boland et al. (2005), who observed that the rate of unintentional injury mortality was significantly higher in rural residents specifically for deaths related to motor vehicle trauma, drowning, machinery, and firearms. Many factors are possible contributors to the increased mortality and injury incidence rates observed among rural populations. Some injury mechanisms may occur more frequently in rural than urban populations; for example, 
motor vehicle crashes may occur more frequently on rural roadways because of their bad design as regard guiding marks and illumination. Other injury mechanisms may be present only in rural environments, an example being injury risks posed by agricultural work (Peek-Asa et al., 2004).

Homicidal deaths were found to be the most common manner of unnatural deaths in the present study, followed by accidental deaths then suicidal deaths. In contrast to these results were those obtained by Ambade et al. (2007) who found that suicide rate per year was higher than homicide rate per year over a period of three years 1998-2000 in Maharashtra, India. Higher rates of suicide in certain localities may be due to absence of religion and lack of faith.

Traumata were the commonest cause of unnatural death in this study especially homicidal. On the other hand toxicity, mostly suicidal and accidental was the least cause of unnatural death. These finding are in agreement with those of Ambade et al. (2007) who observed that poisoning was the commonest method of suicide whereas injuries due to infliction of blunt trauma were the most common method of homicide.

In some autopsied cases the exact cause of death is undetermined when there is a combination of natural processes and external factor as injury which is insufficient solely to cause death. In these conditions preference is given to diagnose these cases as unnatural deaths (Davis, 1997).

In the present study, blunt head injuries especially homicidal were the first leading cause of unnatural death, followed by stab in the chest whereas asphyxias especially smothering and hanging represented the minimal causes. These coincide with the findings of studies of Fisher et al. (1994) and Perry and France (1998) in other countries. In contradiction to these findings the studies of Min Lo et al. (1992) and Avis (1996) reported that deaths due to sharp force including both stabbing and cutting injuries were more common than blunt trauma in New Zealand and Newfoundland, Canada. Deaths due to shooting were less common and this may be due to strict legislation of firearm possession in Egypt. However, in the United States, firearms were the most common weapons of homicide (Lowry et al., 1988).

These differences in the type of trauma may be because of the availability and choice of the weapon used in a different societies and cultures. For instance, firearms are considered to be very uncommon in Eastern countries because of the strict law relating to the possession of the weapon and religious matters, whereas this rule 
does not apply in all over the world including Europe (Preti and Miotto, 2000).

Intoxication with pesticides was found to be the commonest cause of deaths due to poisong in the present study especially carbamate poisoning, followed by organophosphorus and lastly zinc phosphide poisoning. Higher proportion of pesticide poisoning in the present study was probably due to easy availability and increased exposure to these hazardous substances. On the other hand lower rates of alcohol intoxication were found which may be attributed to the control on its use by religion and laws in Egypt. These observations coincide with the study of Singh et al. (2003) who observed an increase in mortality because of various toxic agents with male preponderance especially due to ingestion of pesticides in the Chandigarh zone of north - west India. In Taiwan, Japan (Satoh and Hosokawa, 2000) and SriLanka (Hattiarachi and Kodithuwankku,
1989) organophosphorus compounds were reported to be one of the major causes of unnatural deaths. On the other hand, in western countries, pharmacological agents were reported to be the common causative agents in cases of poisoning (Wynne et al., 1987).

As the population continues to increase, preventive measures need to be taken to minimize unnatural deaths whether homicidal, suicidal or accidental, based on the identified risk factors. Therefore, a more comprehensive and strict legislation should be considered to promote a nonviolent community. In addition, improvement of roadways as well as strict traffic laws must be proposed to control traumatic accidental deaths. Education of agricultural workers about risk factors that lead to accidental poisoning with pesticides should be done. Lastly, strict rules should be present to control marketing of pesticides and pharmacologic agents. 


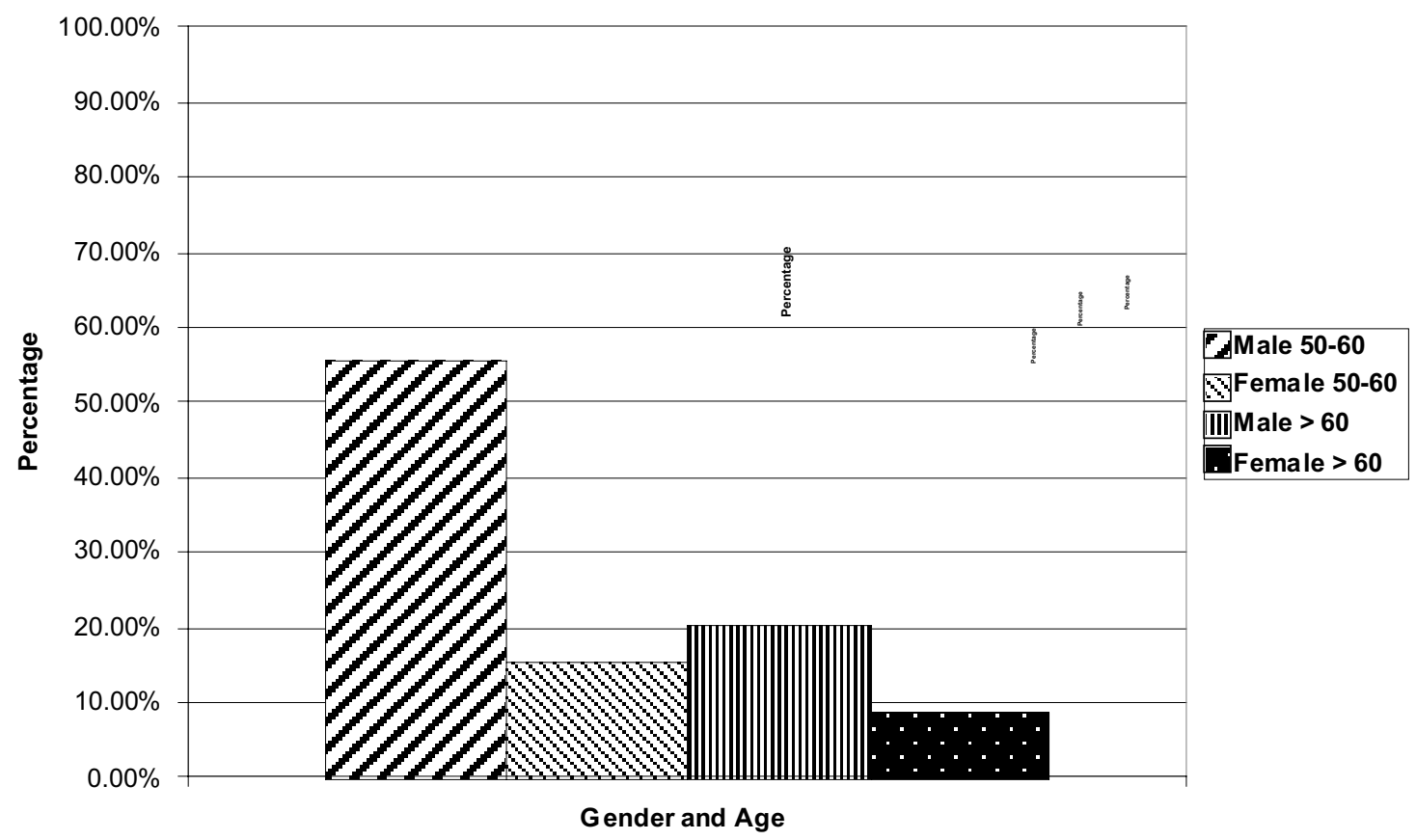

Fig. (1): Comparison between mean percentages of unnatural deaths in old males and females above 50 years allover the period of the study.

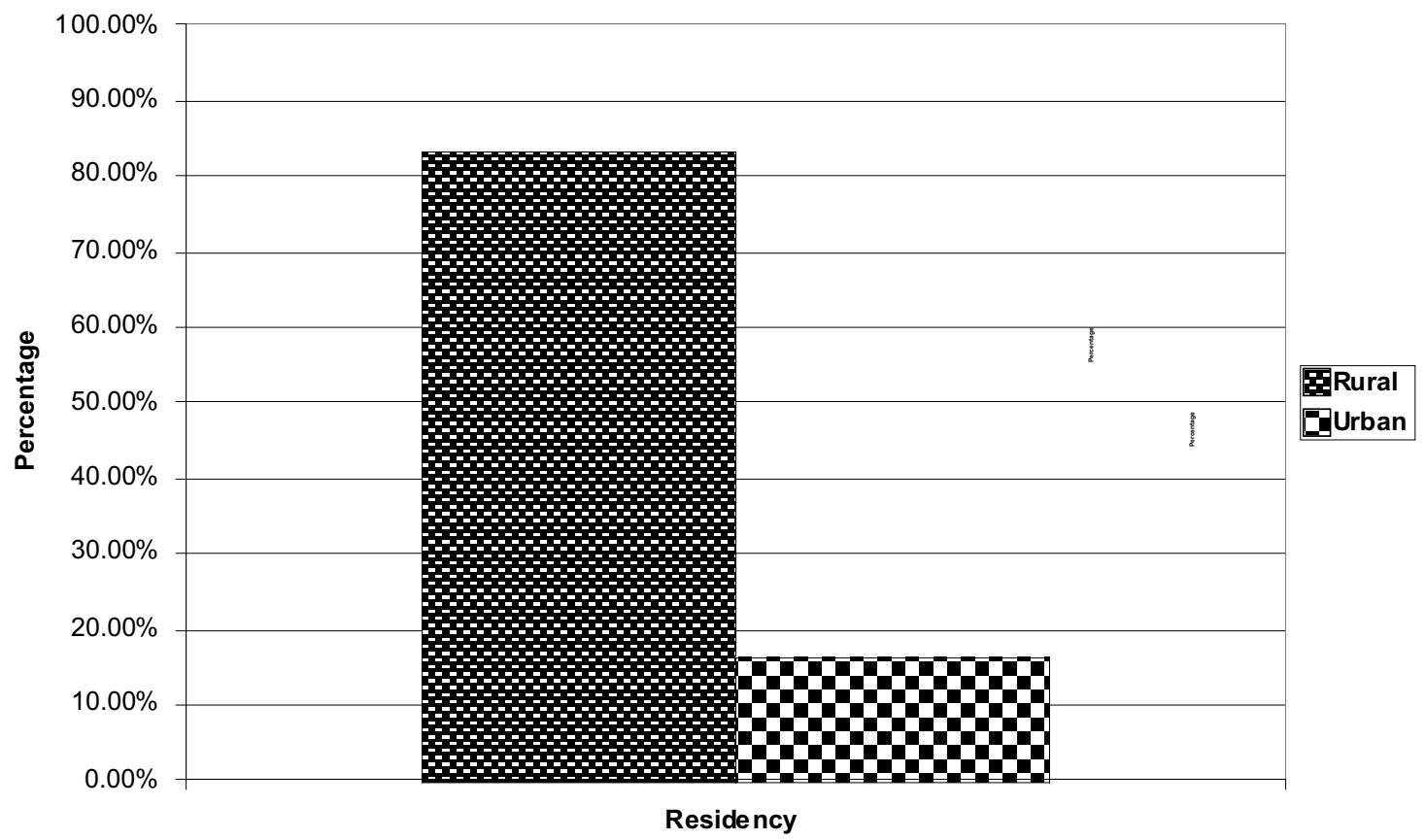

Fig. (2): Comparison between mean percentages of unnatural deaths of old persons in both rural and urban areas allover the period of the study. 


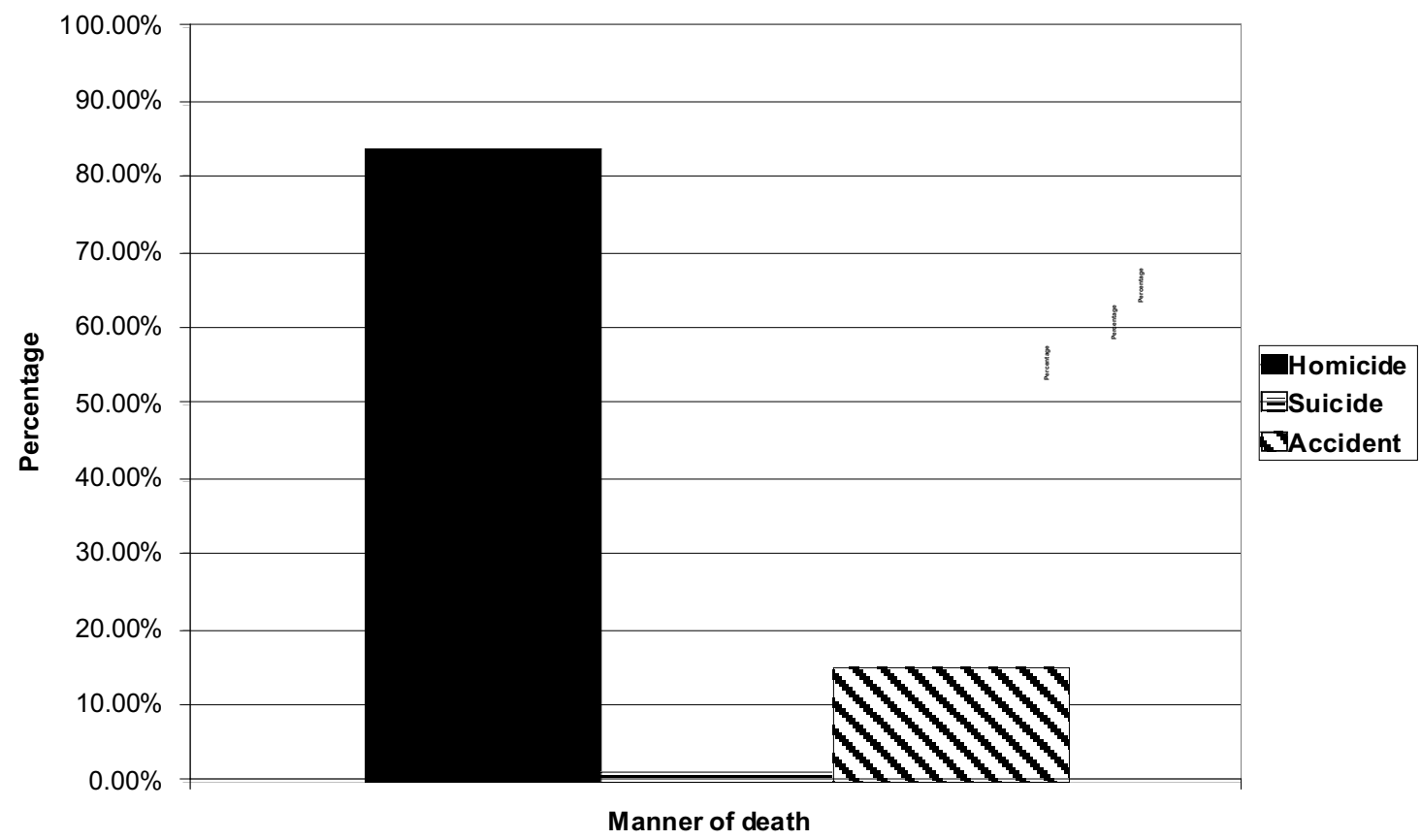

Fig. (3): Comparison between mean percentages of different manners of unnatural deaths in old persons allover the period of the study.

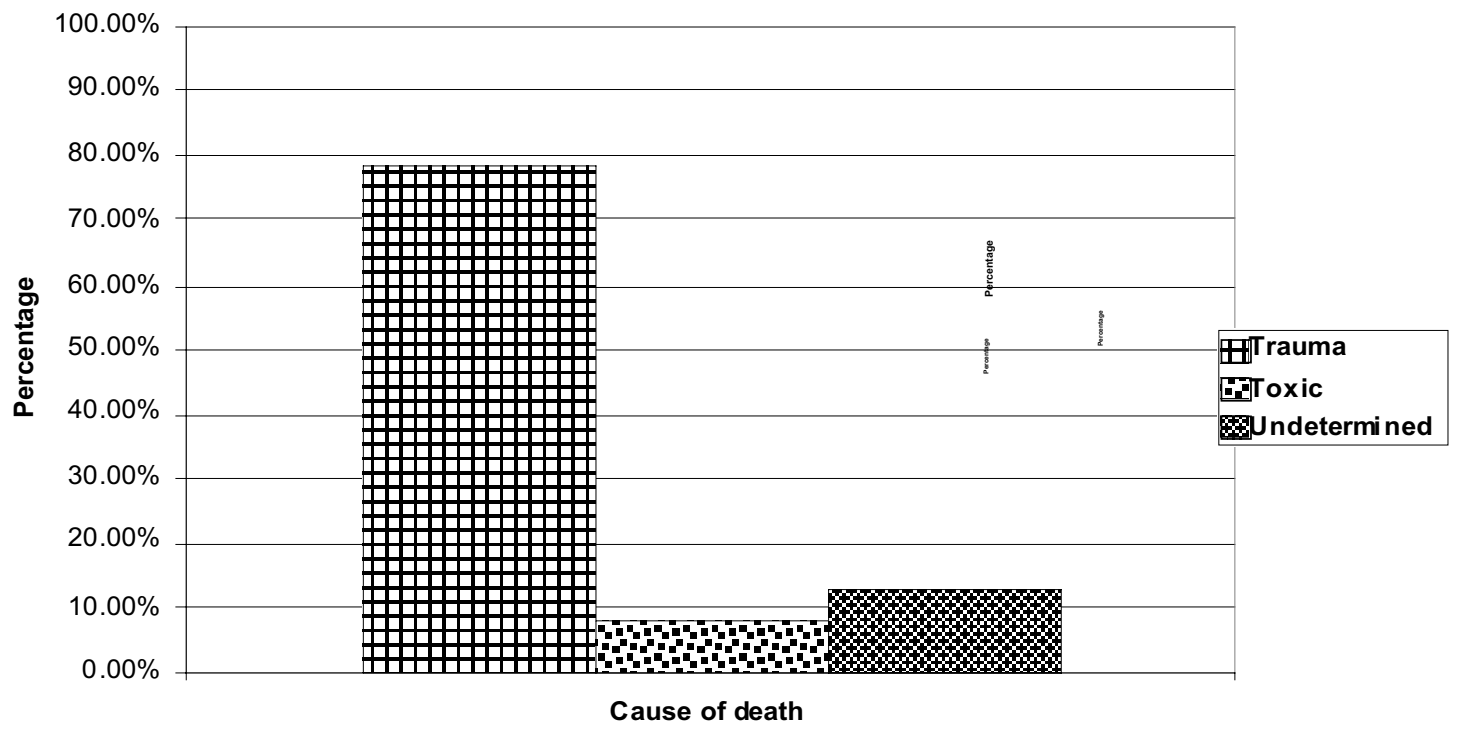

Fig. (4): Comparison between mean percentages of different causes of unnatural deaths in old persons allover the period of the study. 


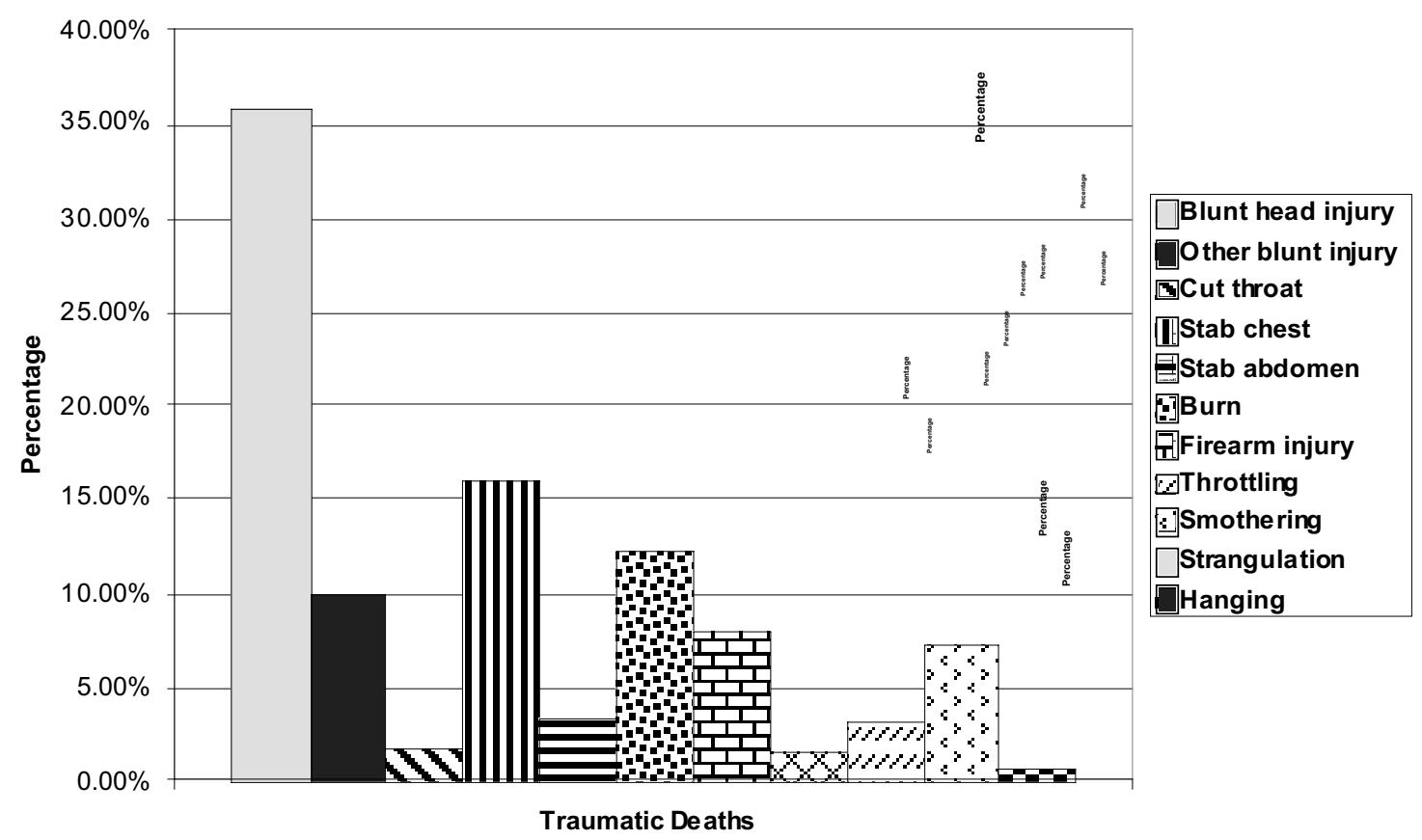

Fig. (5): Comparison between mean percentages of different forms of traumatic deaths allover the period of the study.

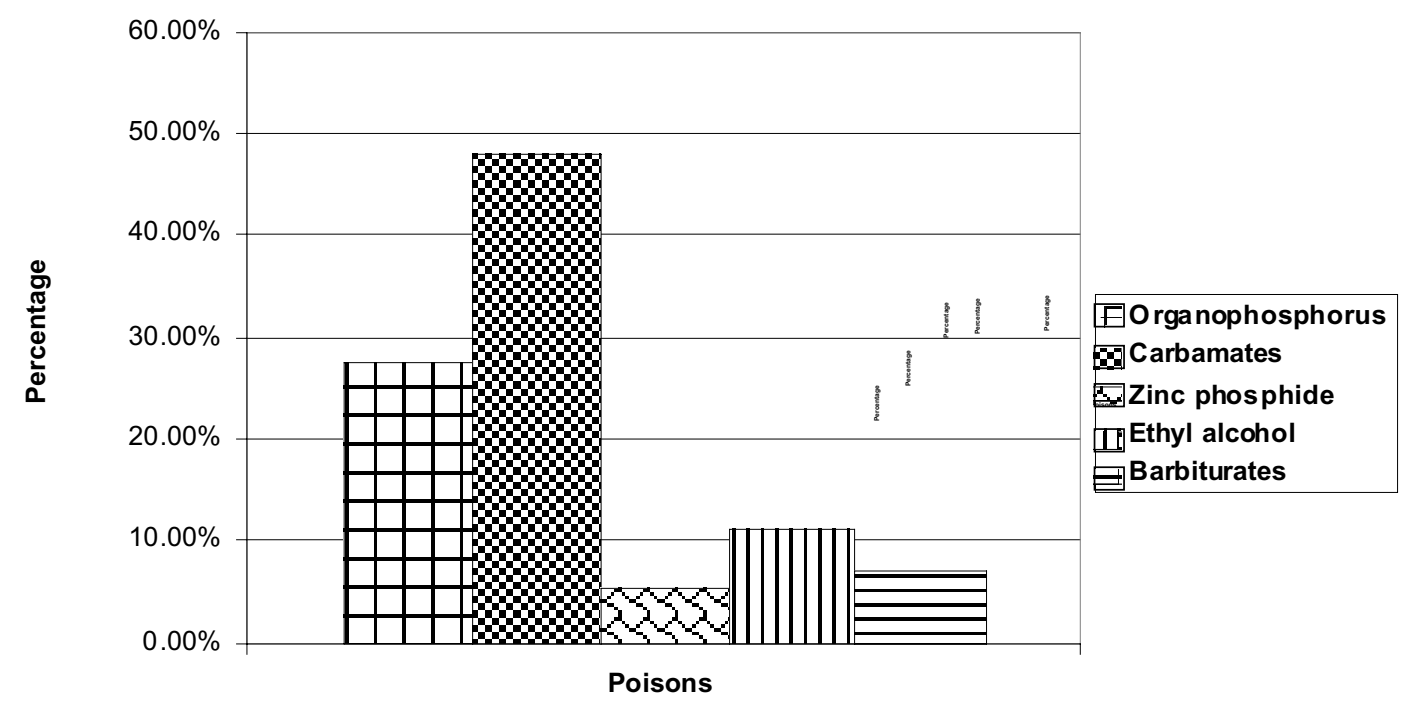

Fig. (6): Comparison between mean percentages of different forms of toxicological deaths allover the period of the study. 


\section{REFERENCES}

Ambade, V. N.; Godbole, H. V. and Kukde, H. G. (2007) : "Suicidal and homicidal deaths: A comparative and circumstantial approach". J. Forensic and Legal Med., 14:253-260.

Avis, S. P. (1996) : "Homicide in Newfoundland: A nine-year review". J. Forensic Sci., 41:101-105.

Boland, M.; Staines, A.; Fitzpatrick, P. and Scallan, E. (2005) : "Urban-rural variation in mortality and hospital admission rates for unintentional injury in Ireland". Inj. Prev., 11:38-42.

Davis, G. G. (1997) : "Mind your manners Part I: History of death certification and manner of death classification". Am.J. Forensic Med. Pathol., 18(3):219-223.

Fisher, J.; Kleemann, W. J. and Troeger, H. D. (1994) : "Types of trauma in cases of homicide". Forensic Sci. Int., 68:161-167.

Hattiarachi, J. and Kodithuwankku, C. S. (1989) : "Pattern of poisoning in rural Sri Lanka". Int. J. Epidemiol., 18: 418-422.

Kumar, V.; Li, A. K. M.; Zanial, A. Z; Lee, D. A. and Salleh, S. A. (2005) : "A study of homicidal deaths in medico-legal autopsies at UMMC, Kuala Lumpur". J. Clinical Forensic Med., 12:254-257.
Lowry, P. W.; Hassig, S. E.; Gunn, R. A. and Mathison, J. B. (1988) : "Homicide victims in New Orleans: recent trends". Am. J. Epidemiol., 128:11301136.

Milroy, C. M. and Ranson, D. L. (1997) : "Homicide trends in the state of Victoria, Australia". Am. J. Forensic Med. Pathol., 18:285-289.

Min Lo, M., Jane, C. V. and Koelmeyer, T. D. (1992): "Homicide in Auckland, New Zealand, a 14 year study". Am. J. Forensic Med. Pathol., 13:44-49.

Mohanty, M. K.; Kumar, T. S. M.; Mohanram, A. and Palimar, V. (2005) : "Victims of homicidal deaths - an analysis of variables". J. Clinical Forensic Med., 12 : 302-304.

Peek-Asa, C.; Zwerling, C. and Stallones, L. (2004) : "Acute Traumatic Injuries in Rural Populations". Am. J. Public Health, 94(10):1689-1693.

Perry, M. J. and France, G. (1998) : "Changing patterns of homicide in Yorkshire and Humberside". Med. Sci. Law, 28:252-255.

Preti, A. and Miotto, P. (2000) : "Death by homicide in Italy, 1980-94: age and gender differences among victims". Med. Sci. Law, 40:233-240. 
Satoh, T. and Hosokawa, M. (2000): "Organophosphorus and their impact on the global environment". Neurotoxicol., 1 (1-2): 223-227.

Singh, D.; Dewan, I.; Pandey, A. N. and Tyagi, S. (2003) : "Spectrum of unnatural fatalities in the Chandigarh zone of north - west India - a 25 year autopsy study from a tertiary care hospital". J. Clinical Forensic Med., 10:145-152.
Vougiouklakis, T. and Tsiligianni, C. (2006) : "Forensic and criminologic aspects of murder in North-West (Epirus) Greece". J. Clinical Forensic Med., 13: 316 320.

Wynne, H.; Bateman, D. N. and Hassanyeh, F. (1987) : "Age and self poisoning: the epidemiology in New Castle upon tyne in the 1980s". Hum. Toxicol., 6 : 511515. 


\title{
دراسة للوفيات الغير طبيعية لكبار السن فى الجثث الهشرحة بالطب الشرعى بمنطقة الدقهلية
}

\author{
المشتركون فى البحث
}

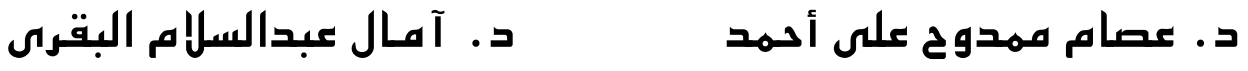 \\ د. هـــود أحمد على \\ من قسم الطب الشرعى والسموم الإكلينيكية - كلية الطب - جامعة المنصورة

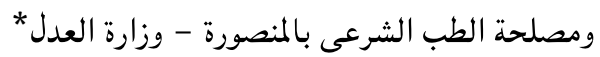

إســهـفت هـذه الدراسـة تحديد الأسـباب والأوجـه السـائدة فى الوفيـات الغير طبيعية لكبـار السن، تم تجميع بيانات عن عدد الج من

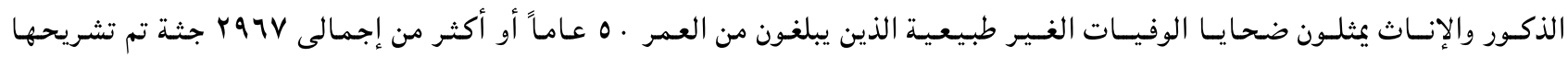
بواسطة مصلحة الطب الشرعى بالمنصورة التابعة لوزارة العدل على مدى عشرة سنوات من عام 1997 إلى عام ه . . ب. كان عدد الضحايا من

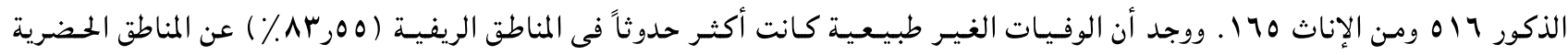

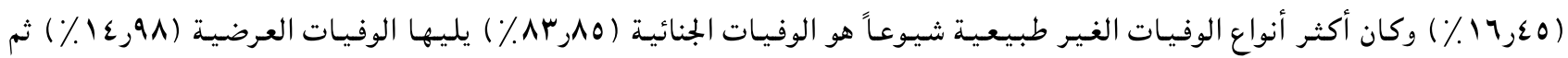

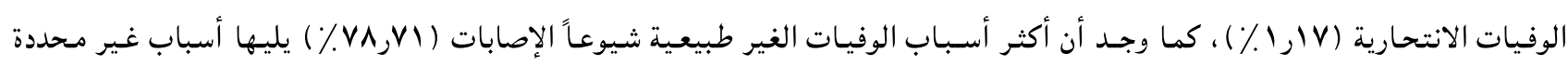

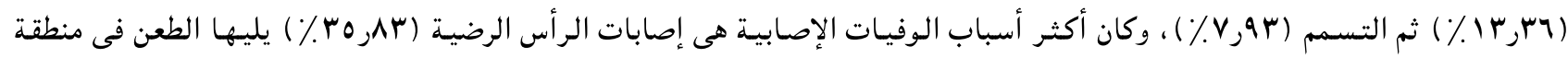

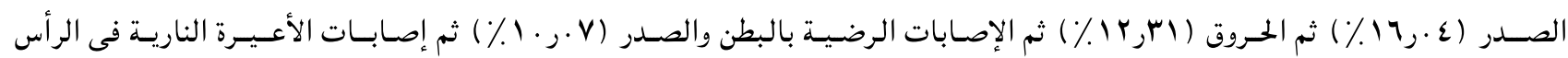

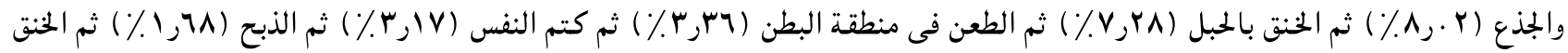

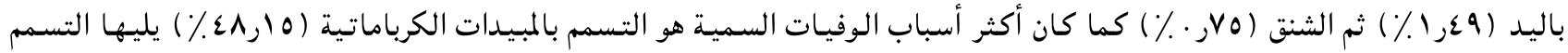
بالمبيدات الفوسفورية العضوية (YVVV بفوسفيد الزنك (0,07\% ). 